\title{
Francia y la segunda guerra del Vietnam
}

\begin{abstract}
PHILIPDE DEVILLERS es un historiador y escritor francés que vivió en Victnam durante la Primera Guerra de Indochina. Sus Histoire du Viât-Nam de 1940 à 1952 (Paris, Le Seuil, 1952) y La fin d'une gucre: Indochine 1954 (Paris, Le Seuil, 1960), escrito con Jean Lacouture, son considerados como textos fundamentales por todos los especialistas en el sucleste asiático. Es actualmente también editor de la revista France-Asie, Parfs.
\end{abstract}

Cada semana que pasa en Vietnam no sólo enfrenta a vietnamitas y norteamericanos sino que además obliga a enfrentarse al Tercer Mrundo y al mundo anglosajón. No parece evidente que esta guerra termine por replantear algún día la "coexistencia pacífica"; pero como ella se ha tornado en una prueba de fuerza entre el munclo rico y el mundo pobre, arriesga afectar por muchos años la escisión política de la humanidad. Ella es, aunque sólo fuera por esta razón, de una importancia capital para los pueblos europeos.

Sobre este problema del Vietnam, Francia ha acloptado, desde hace más de seis años una actitud y una política cada día más divergente de la asumida por Estados Uniclos y que incluso se opone a ésta. Estas divergencias repercuten sobre el plano atlántico y arriesgan afectar seriamente en el porvenir, la naturaleza de las relaciones francoestadouniclenses. Es en efecto una otra "Norteamérica", una Norteamérica muy distinta de aquella que había sido idealizada después de Lafayette y de 1917, la que ahora Francia clescubre a medida que prosigue la guerra cle Vietnam:

Numerosos malentendidos, interpretaciones fantasiosas $y$ aun burdas distorsiones han acogido las diversas manifestaciones cle la poLítica francesa en lo que respecta a Indochina. Es por esto que nos pareció importante $y$ útil explicar en cletalle, y yendo a las fuentes, cómo Francia se ha llegaclo a interesar de nuevo en Indlochina, por qué está en desacuerclo con la política seguicla por Estados Unidos en esta región, por qué propone una solución razonable y pacífica, basándose en la neutralidad de los Estados Indochinos. 
Los acuerdos de Ginebra, que en julio de 1954 habian puesto fin a la guerra de Indochina, provocaron un abandono territorial y militar prácticamente total de Francia en Asia. El Vietnam del Norte había sido evacuado en mayo de 1955, el Vietnam del Sur lo fue en abril de 1956. Después cle la restitución de las cinco posesiones a la India (en 1955) habian queclado solamente misiones militares en Camboya y Laos, por expresa solicitud de los gobiernos de Vientiane y de Phnom Penh. Solamente la participación de Francia en la OTASE le permitía mantener cierta responsabilidad en el resguardo de la paz en el sudeste asiático.

Convendría recordar que en la base de los acuerdos de Ginebra había un convenio tácito entre el Este y el Oeste, según el cual Indochina ( $y$ tal vez más adelante otras) constituiría, en adelante, una zona política y militarmente neutralizada, en donde las grandes potencias se abstendrían cle intervenir. Pekín, desde junio de 1953, había dado a entender al jefe de la primera misión económica francesa que China se uniría de común acuerdo a dicha fórmula.

El gobierno de Bao Dai/Ngô Dinh Diem, que la 4ạ República organizó en Saigón, había por supuesto rechazado los acuerdos, y aunque era el fruto de una construcción jurídica muy discutible, fue entonces consideraclo en París, como el único "gobierno legítimo de todo Vietnam". Desde 1945 Francia había reconocido la unidad del Vietnam, aspiración fundamental del nacionalismo vietnamita. Durante la con: ferencia de Ginebra había reafirmado que esta unidad no podrá ser reconsiderada ${ }^{1}$. Sabemos que Estados Unidos y Gran Bretaña adoptaron la misma actitud y precisaron que la línea de demarcación militar no tenía una significación política. Washington y Londres confirmaron públicamente, en noviembre de 1954, este deseo de considerar al Vietnam como una sola nación². Por lo demás, el gobierno

1En' una carta a Bao Dai (del 6 de mayo de 1954), G. Bidault, Ministro de Relaciones Extcriores del gabinete Lanicl, escribia: ". . .nada irfa más en contra de las intenciones del gobierno francés que preparar el establccimiento a expensas de la unidad de Vietnam de dos estados, teniendo cada uno una vocación internacional" (J. Lacouture y Ph. Devellers, La Fin d'une guerre, París, Seuil, 1960, pp. 123-124).

El "tratado de independencia de Vietnam", del 4 de junio de 1954 (acuerdo Laniel-Bü Loc), dice en su artículo 1: "Francia reconoce al Victnam como un estado absolutamente in"dependicnte y soberano investido de todas las facultades reconocidas por el Derccho Internacio: nal" (Documentación Francesa: Articles et Documenls A. D. 6067, 15 de junio de 1954). Este tratado no había sido ratificado ni firmado cuando se firmaron los Acuerdos de Ginebra.

aDe-septiembre a noviembre de 1954, Estados - Unidos y. Gran. Bretaña intentaron -mantener sus Consulados en Hanoi sin pedir ser acreditados por el Gobierno de la República Democrática de Vietnam. Washington y Londres se apoyaron oficialmente en el párrafo de la Declaración final de Ginebra que decía que "el acuerdo relativo a Vietnam tiene por objetivo esencial regular los asuntos militares con miras, a poner tërmino a las hostilidades y que la línea de demar- 
E S T U D I O S I N T ER NA G I O N A L E S

de Diem calificaba de traidores a todos los vietnamitas que aceptaban la división de Vietnam, de lo que eran culpables solamente los comunistas. Esta posición del señor Diem iba a formalizarse en la constitución de la "República de Vietnam", promulgada el 26 de octubre de 1956 y cuyo artículo primero decía: "El Vietnam es una república independiente, unificada, territorialmente indivisible"3.

Aunque hubiera sido conveniente, por la perspectiva de las elecciones previstas para 1956, restablecer y desarrollar contactos con el gobierno de Hanoi, que el bloque socialista consideraba como el único gobierno legítimo de todo el Vietnam, los compromisos contraídos, la presión de la Derecha francesa, la de Estados Unidos y la de Diem limitaron mucho los alcances de la misión de Jean Sainteny, enviado desde octubre de 1954 a Hanoi como "Delegado General de la República. Francesa", causando viva inquietud a Saigón y Washington.

Sin embargo, el Gobierno de Mendès-France, único responsable, del lado occidental, de la ejecución de los acuerdos de Ginebra, hipotecó en algunas semanas su capacidad para hacer frente a estos compromisos. El 8 de septiembre de 1954 firmaba el tratado de Manila que creaba la OTASE. El 29 de septiembre en Washington, Guy Ia Chambre y el General Bedell Smith firmaban secretamente un protocolo consagrando el acuerdo de sus gobiernos respectivos para "sostener a Ngô Dinh Diem en el establecimiento y el mantenimiento de un gobierno fuerte, anticomunista y nacionalista". El 23 de octubre el Presidente Eisenhower al deducir las consecuencias de este abandono de Francia de parte de sus responsabilidades, aseguraba a. Diem el apoyo de Estados. Unidos. El 23 de diciembre, el acuerdo franco-norteamericano (Ely-Collins) abandonaba al jefe del MAAG estadounidense (si bien es cierto que "bajo la autoridad superior del Comandante en Jefe" francés) "Ia plena responsabilidad de la ayuda a prestar al gobierno del Vietnam, para la organización y la instrucción de sus fuerzas armaclas".

Se podría discutir que esto fue contrario a lo que los acuerdos de Ginebra decían textualmente. Pero de lo que no hay duda es que los protocolos franco-norteamericanos de septiembre $y$ diciembre estaban en contra del espíritu de los acuerclos y los peligros de esta orientación se percibian ya claramente. Desde el 19 de enero de 1955 Pham Van Dong, en Hanoi, decía públicamente a los periodistas: "Es con Uds., franceses, con quienes firmamos los acuerdos de Gi-

cación militar es una línca provisoria y no podría ser interpretada de ninguna manera como que constituya un límite político o territorial".

'Las cartas provisorias del 20 de octubre de 1964 o el 16 de junio de 1965, confirmaron: "Vietram es una república: su territorio es uno c indivisible". 
nebra. A Uds. incumbe hacerlos respetar en la zona de la que sois responsables"4.

Por último, el pacto de Manila estableció en la región un sistema de seguridad colectiva en el cual Francia participaba. Para suavizar al menos el texto de Ios acuerdos de Ginebra, a los Estados de Indochina se les protegió con un protocolo especial.

Un contrataque a una eventual agresión, no puecle llevarse a efecto aqui si no es solicitado expresamente por los Estados de Indochina, y a condición que sea decidido de común acuerdo por los que suscribieron el acuerdo. El promotor del Tratado, Foster Dulles, insistía en el aspecto colectivo, fundamental a sus ojos, del compromiso. $Y$ las interpretaciones que el Secretario de Estado dio clel Tratado, en esa época, eran restrictivas y tranquilizadoras. Al parecer, no habría lugar para las aventuras.

El comienzo de la guerra cle Argelia (en noviembre de 1954) apartaría largo tiempo a Francia del Extremo Oriente. A partir del 19 de enero de 1955, la ayuda norteamericana llegó a Vietnam, convertido en país plenamente "independiente", no ya por intermedio de Francia, sino directamente.

Descle principios de 1955, Estados Unidos, inquieto por el aumento del neutralismo en la región, aumento que iba a acelerar la conferencia de Bandung, se cledicó a hacer de la OTASE una cadena de estados a la vez antichinos $y^{\prime}$ anticomunistas. A fines de 1955, Foster Dulles trató de obtener del Príncipe Sihanouk la adhesión de Camboya a la OTASE. De hecho, instigada por las presiones norteamericanas e influenciada por Nehru, Camboya se orientaría rápidamente hacia la neutralidad y se esforzaría por establecer relaciones normales primero con la Unión Soviética y luego con China.

Si bien es cierto que París no juzgaba al gobierno de Diem representativo o capaz de realizar en Vietnam del Sur la unión tan deseada de las facciones políticas u otros grupos ${ }^{\tilde{0}}$; el gabinete de Guy Mollet, sin embargo, aceptó la solicitud de evacuación presentada a comienzos de 1956 por Saigón. El 28 de abril de 1956 las últimas tropas francesas abandonaban Vietnam del Sur. Francia habia mantenido sus compromisos con el "gobierno" vietnamita que ella había suscitado desde 1948 para tratar de mantener su control sobre el país.

Aplicó sin ducla estrictamente las cláusulas militares del acuerdo clel 20 de julio de 1954; no hizo, sin embargo, respetar ni aplicar ninguna de las disposiciones políticas: prohibición de tomar represalias

\$Max Clos, Le Monde, 3 de enero de 1955.

oEdgar Faure, Presidente del Consejo, habia indicado claramente desde el verano de 1955 que a los ojos del gobierno de Paris, Diem no cra ni capaz de realizar la unión nacional, ni era representativo de la poblacion del Sur. 
contra las personas partidarias cle los adversarios (Art. 14c del acuerdo militar), libertades democráticas (Art. 14c). Por otra parte, dejó que la influencia norteamericana reemplazara la suya propia, violando completamente los acuerdos (Arts. 16 al 19), haciendo así muy difícil, si no imposible, la neutralización de Indochina, uno de los objetivos esenciales de la Conferencia de Ginebra. Observadores entendidos se preguntan hoy día si esta "cesión" del Vietnam del Sur a Estados Unidos se habría producido si el General de Gaulle hubiera llegado al poder cuatro años antes.

Esta violación de las convenciones ponía en peligro el mismo cese del fuego, que no fue aceptaclo por la RDVN, sino con la promesa de elecciones ${ }^{6}$. Las potencias temían que la partida cle las fuerzas francesas fuese el pretexto para la RDVN de reiniciar la lucha interrumpida al día siguiente de Dien Bien Phu. Presionaron a Diem para que retomara los compromisos franceses a su cargo. Incluso Washington insistía en esta época, pues era el único medio de consolidar la división de Vietnam y' de evitar las elecciones previstas. Diem prometió sucesivamente no adherir a ninguna alianza militar y no aceptar ninguna base militar de potencias extranjeras ( 6 de abril de 1956), Iuego respetar el pacto de armisticio (14 de julio de 1956). En șuma, a pesar de una nueva prolongación de la división administrativa provisoria del Vietnam, los objetivos fundamentales de los acuerdos de Ginebra se podian considerar a salvo. El Norte y el Sur permanecian, en principio, "neutralizados".

Esta "mentalidad militar" no tenía por qué estancar la vida política. El cese del fuego no implicaba en absoluto una cesación de las actividades politicas de la izquierda o de la derecha. En la medida en que el gobierno de Diem hubiera sabido conciliar las masas rurales y urbanas y normalizar sus relaciones con el Norte, habría includablemente llegado a consolidar la división ${ }^{7}$.

Es la política norteamericana la que iba a quebrantar y a minar este frágil edificio. En Washington el State Departement (Foster Dulles, Walter Robertson, etc.), la c.I.A. (Allen Dulles), como también el Pentágono (Almirante Radford), consicleraban a Indochina como la base de la posición anticomunista en el sudeste asiático. Ejercieron pues presiones cada vez más intensas en 1956 (cuando se vio que Camboya, Laos e Indonesia establecían relaciones normales con P.ekín, que Birmania desarrollaba las suyas); luego en 1957, en Laos, donde al fin el acuerdo logró intervenir entre:el gobierno de Souvanna

\footnotetext{
"Remitase al acto de la conferencia de Ginebra, por ejemplo, J. Lacouture, op. cit., p. 268 y también el artículo 14a del acuerdo sobre la cesación de las hostilidades en Victnam.

'Londres y Moscú se remitieron a negociaciones directas entre. Saigón y Hanoi, preocupándose de decidir la fecha de las elecciones generales "en el momento más oportuno".
} 
Phouma y el Pathet Lao, legitimanclo a este último y ofreciéndole una participación en el gobierno. Para contener el desarrollo de los regimenes neutralistas, que en Washington juzgaban demasiado débiles para poder detener al comunismo, fuerzas a menudo reaccionarias fueron directamente impulsaclas para resistir, en caso necesario por las armas, a los compromisos que gobiernos legítimos y responsables habían celebrado (o buscaban hacerlo) con la izquierda.

Para justificar esta intervención cle las fuerzas conservadoras, y la ayuda norteamericana que se les proporcionaba, las actividades comunistas fueron clescritas de manera cramática y a menudo inexacta ${ }^{8}$. La G.r.A. intervino directamente en Laos y aun en Camboya. Para hacer frente a la guerrilla que continuaba en el oeste de la Cochinchina, a las sectas Hoa Hao, Binh Xuyen y a algunas unidades católicas (Vardo) o Lao Dai", para contener también los progresos cle los "moderados"; Diem fue a Washington, en mayo de 1957, para peclir ayucla financiera. La compensación aparente de ésta iba a ser una intensificación de la represión, tan violenta esta vez, que la guerra civil se produciría.

La ayuda militar de Estados Uniclos fue aumentada. El ejército de Vietnam del Sur estaba muy bien pagado y'a con fondos de origen norteamericano, y lo fue más aún. La formación de una "nueva clase" militar, mantenida gracias a la ayucla extranjera, con un interés directo en mantener; o aún más, en crear tensiones que justificaran su existencia, es una de las características esenciales de Vietnam del Sur y de Laos, de 1955 en adelante, y los presupuestos locales, incapaces de sostener fuerzas armadas pletóricas caen en una dependencia cada vez mayor de la ayuda financiera norteamericana.

La independencia clel gobiemo, de ahora en adelante, no es más que una ficción.

Durante años Francia no tomó posición alguna, públicamente al menos, sobre estos problemas de Indochina. La guerra de Argelia, transformada en el problema crucial de la política interior y exterior francesa, aislaba a Francia de la mayoría de los países de Asia y Africa, quienes denunciaban su carácter de "colonialista". Poner fin a la guerra de Argelia era pues un imperativo categórico si se quería devolver a Trancia el total clominio de su política extranjera.

Habiendo llegado al poder en junio de 1958, el General de Gaulle, a través de etapas sucesivas, se encaminaría hacia un arreglo del problema argelino basándose en la autodeterminación y en la indepen-

\footnotetext{
oRemitirse a la Declaración de Sir Anthony Eden a los Comunes el día 8 de noviembre de 1954; a la de Frédéric-Dupont en París el 10 de noviembre de 1954; a la nota del Alto Comando de las Fuerzas de la Unión Francesa a la c.1.c., Saigon, 27 de noviembre de 195.

"Ellas constituyeron en 1957 el "Frente de Unión Nacional y de. Revolución", junto: con antiguos Viet Minh.
} 
dencia. Fuera cle esto, la vuelta a la estabilidad gubernamental, el saneamiento de la situación financiera y económica, devolvían a Francia los medios para ejercer en el exterior una política, esta vez, independiente.

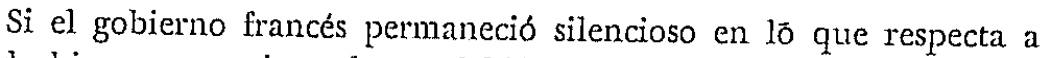
Indochina, no era sin embargo debido solamente a la guerra de Argelia. Era también para no entorpecer la acción de Estados Unidos, potencia aliada. Pero el desarrollo de la guerra civil en Vietnam, tan lleno de peligros, no podía dejar a Francia indiferente y debía forzarla a superar los complejos que podía tener respecto a esta región. Camboya, para salvaguardar su independencia, mantenía un juego sutil entre China y la Unión Soviética por un lado, y Estados Unidos por el otro, y deseaba obtener el apoyo de Fuancia. Olas sucesivas de exiliados políticos provenientes de Saigón, huyendo de la represión y las purgas, llegaban a París. Aun, jefes militares del Ejército de Saigón venían a pedir ayuda.

De hecho, la situación de Indochina se agravaba rápidamente y empezaba a constituir una fuente de inquietud internacional. La guera civil en Laos, avivada en 1958 después del golpe de estado de la Derecha, impulsado por la c.I.A., se había detenido momentáneamente en 1959, después que una comisión de información de la ONU demostró la nulidad de las afirmaciones de Vienciane según las cuales el país había sido invadido por los norvietnamitas. Pero París estaba mucho más preocupado del aparente éxito de Diem, quien, inventando como lo habian hecho ya los laosianos, pretendidas infiltraciones del Norte, lograba, en la primavera de 1960, persuadir a determinados medios en Washington que en las mesetas había "agresión comunista"10. Todos los informes disponibles en París mostraban en efecto que no había en esta región "infiltración" exterior, sino solamente reacción de tribus montañesas a la política torpe de los funcionarios de Saigón. Se sabía en París que los sudvietnamitas "fabricaban pruebas" y que los norteamericanos eran tan "ingenuos" que les creían11. También se sabía en París que desde principios de 1958 el "Frente de Unión Nacional y de Revolución" se había aliado a un "Frente Nacional de Liberación de Vietnam del Sur" (Mat-Tran Dan-Toc Giai-Phong Mien-Nam Viet$\mathrm{Nam}$, cuya existencia atestiguan varios informes norteamericanos y sudvietnamitas ${ }^{12}$. Hanoi parecía inquieto por el desarrollo de este

\footnotetext{
10Los primeros telegramas relativos a operaciones en las altas mesetas de Vietnam datan de abril de 1960.

„1Esta historia es contada, con nombres ficticios, en el libro reciente de W: J. Lederer y E. Burdick, Sarkhan, Nueva York, 1966 (aparecido en Francia bajo el título de Les Fourmis rouges, Paris, Scuil, 1966).

22Remitirse en particular a Gerald C. Hickes, Village in Vietnam, New Haven. London, 1964, p. 10; : Vielnam Presse (Bulletin d'Ecoutes), del 29 de junio de 1958, Saigóri.
} 
Frente ${ }^{13}$ y multiplicaba ofrecimientos de negociación a Saigón que eran rechazados uno tras otro.

En 1959 las Fuerzas Armadas de Liberación del Sur, en el seno de las cuales los Binh Xuyen así como los Hoa Hao ocupaban ahora un lugar importante ${ }^{14}$, pasaron al primer plano de la contraofensiva. Desde el mes de marzo de 1959, Diem decía que la guerra hacía estragos en el Sur'15 y promulgaba su famosa ley cie represión No 10/59. Ahora bien, la acción armada se clesarrollaba enteramente en el sur, en la región vecina al Mekong clonde no se encontraba la más mínima huella de infiltración norteña.

París sabía exactamente a que atenerse en lo que se refería a los origenes de la resistencia armada en Vietnam del Sur. Sus fuentes de información eran, por lo demás, mejores que las de Washington. Todas las informaciones serias concorclaban: nos encontrábamos en presencia de un levantamiento cle varias regiones rurales contra una administración corrompida o contra los métodos de una policía bajo las órdenes de grupos de intereses (casi todos uniclos a los refugiados o a grupos del Norte). En marzo de 1960, para precisar su posición en el seno cle una alianza en la que eran minoritarios, los antiguos cuadros vietminh clel Sur, publicaron una larga declaración en la que decían por: qué la resistencia armada era de ahora en adelante la única solución posible, pero en la que también volvían a peclir al gobierno cambiar su polf́tica ${ }^{10}$. Un mes más tarde, el 26 de abril de 1960, personalidades políticas de Saigón hablaban en el mismo tono (Manifiesto de los Dicz y Ocho).

Es en ese momento que para disminuir la presión y también por influir sobre la elección presidencial norteamericana, Diem "inventó" la agresión del Norte. A fines del año, justo después de la elección del Presidente Kennedy, un golpe de estado militar, impulsado por ciertos

13Editorial de Nahn Dan, Hanoi, el 28 de junio de 1958, citado por Radio Fanoi (citado en Vielnam Presse, Saigón, 29 de junio de 1958); emisión de Radio Hanoi, el 10 de julio de 1958, etc.

Las notas del gobierno de Hanoi al de Saigón, con fecha 7 de marzo de 1958, son una proposición de negociación detallada y constructiva. Esta fue renovada bajo diversas formas por las notas del 7 de mayo y 22 de diciembre de 1958, del 4 de octubre de 1960, etc.

14Hecho confirmado por informes norteamericanos, en particular por $A$ Note on the Victuamese Sects, U.s., Mission in Victnam, JuSPAo, Saigón, mayo 1966 ('Texto parcialmente citado por Bernard Fall, "Vietnam in the Balance", Foreign Alfairs, Nucva York, octubre de 1966, p. 12).

25) Declaración de Ngô Dinh Diełn a Serge Groussard: "Victnam es una nación democrática, joven, en estado de guerra. . . Cuando se lucha por su existencia, las necesidades de cste combate por la vida priman" (Le Figaro, 24 de marzo de 1959).

10Su texto en francés fue publicado en París en mayo-junio de 1960, bajo el título "De Corea a Vietnam". Comentario sobre la declaración en $L^{\prime} E c h o$ du Victnam, París, No 2, julio de 1960, p. 4. Ver también sobre la oposición a Diem, Le Figaro, París, 20 de abril de 1960. En ese momento fue cuando Saigón creó su "Comisión Especial para la Liberación del Norte y la Reunificación del Pais', contra la cual Nhan Dan, IFanoi, protesta el 11 de abril de 1960 (A.F.P. Hanoi, 11 de abril de 1960). 


\section{EST U D I.OS I N TER NA CIONALES}

elementos norteamericanos, fracásaba en Saigón (el 11 de noviembre de 1960). Juzgando que era el momento para salir de la clandestinidad, el Frente Nacional de Liberación de Vietnam del Sur, cuyos comités locales preparaban desde hacía meses su creación, aparecía a la luz del día (20 de diciembre de 1960).

Desde la desaparición de Foster Dulles, París creía que Washington podía ser todavía persuadido para que cambiara de política en Indochina. París pensaba que la situación en esta región podría discutirse sin demora entre las potencias de Ginebra para detener por lo menos las intervenciones cacla vez mayores de Estados Unidos y la Unión Soviética en Laos, donde un nuevo golpe de estado (neutralista esta vez) tenía lugar en agosto de 1960. Ya soviéticos y chinos mostraban sus divergencias en cuanto a la apreciación de la situación en Vietnam ${ }^{17}$.

Conscientes del peligro que podría representar para el mundo una "escalada recíproca", Estados Unidos y la Unión Soviética estuvieron de acuerdo en buscar una solución teniendo como base la neutralidad de Laos. En Viena, a comienzos de junio de 1961, Kennedy y Klurushchev dieron la señal de la "desescalada" mutua que por medio de una nueva conferencia de Ginebra y un acuerdo de las tres facciones laosianas en Zurich, terminaría en los acuerdos del 6 de junio de 1962.

Pero un acuerdo sobre Laos no podía ser efectivo y durable si el problema de Vietnam no era en sí mismo resuelto o por lo menos estuviese en vías de ello. Moscú habría podido obtener, gracias a sus tiempos laosianos, concesiones en Washington ${ }^{18}$. Pero Kennedy no aceptó discutir sobre Vietnam, que consideraba con cierta inconsciencia como un problema puramente norteamericano. Sin embargo, en esa época no había todavía hecho su elección.

Con todo, el problema no era toclavía muy complejo. Presionado por grupos vietnamitas antidiemitas ${ }^{10}$, el General de Gaulle intervino, precisándole al Presidente Kennedy, durante su entrevista en París (el 19 de junio de 1961), que el conflicto de Vietnam no era sino marginalmente militar, a sus ojos, y que por lo tanto no admitía una solución militar. Dijo entonces el Presidente de la República francesa que era un problema politico que no podía ser resuelto sino por una acción politica. Francia, si era consultada, estaba dispuesta a ayudar a Estados Unidos a encontrar una solución pacífica y honrosa. Se trataba en su-

${ }^{2 \pi}$ Remitirse a los discursos de los delegados sovjéticos (Muklitdinov) y chinos (Li Fu-chun) en el 3.0r Congreso de Lao Dong, IJanoi, 3-5 de septiembre de 1960.

18Ver: Nguyen Manh FIa, 'El problema de Vietnam del Sur es paralelo al de Laos", Combate, París, 8 de abril de 1961; Ph. Devillers, "Vietnam del Sur: Plebiscito y podredumbre", Témoignage Chrétien, París, No 875, 14 de abril de 1961; y entrevista de Ung Van Khiêm, Mfinistro de Relaciones Exteriores de la República Democrática de Vietnam, a propósito de la neutralidad de Vietnam del Sur, Lc Afonde, 28 de mayo de 1961.

10 Memorándum del 28 de mayo de 1961. 
ma de reconstituir en Saigón un gobierno clemocrático y representatiro capaz de poner fin a la rebelión por la negociación.

Pero el Presidente Kennedy' no siguió estos consejos. Tres semanas antes había enviado para "documentarse" al Vicepresidente Lyndon B. Johnson. Este, clespués de dos días de visita (11-13 de mayo de 1961), se había transformaclo en un ardiente clefensor del régimen diemista a cuyo jefe saludó como "el Winston Churchill de Asia". El comunicado norteamericano-vietnamita del 13 de mayo de 1961 fue de hecho una declaración de guerra a la "subversión vietcong".

De vuelta en Washington, por iniciativa del vicepresidente, quien tenía en sus manos todo el programa de ayuda al régimen de Saigón, se tomaban una serie de clecisiones. En junio, la administración Kennedy decidia aumentar el número de "Consejeros Militares" norteamericanos en Vietnam del Sur. En julio una misión dirigida por el profesor Staley establecía un programa "económico" de lucha contra la rebelión: las "aldeas estratégicas". En julio, el cardenal Spellman, impulsado por su amigo Mgr. Ngô Dinh Thuc, enviado especial de su hermano Diem, a Estados Uniclos, movilizaba en favor de Saigón al lobby católico norteamericano. En octubre, por fin, otra misión de clos consejeros personales del Presidente, el General Maxwell Taylor y Walt W. Rostow, llegaba a la conclusión de que el problema era esencialmente militar, que Estados Unidos tenía que proveer al régimen diemista de los meclios materiales (helicópteros, armamentos $y$ "consejeros") que le permitiesen ganar la "guerra especial" que había que librar ahora. El 9 de febrero de 1962, un comando especial común norteamericano-vietnamita era formado bajo la autoridad del General Harkins. Así Washington se comprometía a fondo en la vía diametralmente opuesta a la que el General cle Gaulle había recomendado, después de un macluro análisis, a John F. Kennedy.

\section{OPOSICIÓN FRANCESA A LA ESGALADA NORTEAMERICANA}

La evolución del conflicto vietnamita clesde 1962 ha demostrado que el pueblo del Sur estaba dispuesto a los más grandes sacrificios para poner fin a un régimen repudiado, que con la ayuda extranjera buscó y busca toclavía conservar el poder a cualquier precio. Esta oposición cle gran parte de la población no ha podido ser reducida por la fuerza. Muy por el contrario ella se ha, por lo que parece, desarrollado y endurecido con la guerra. Saigón $y$ Washington se han obstinado, sin embargo, en buscar una "solución militar". El apoyo cada vez más abierto acordado por Estaclos Unidos al régimen oligárquico de la familia Ngô primero, y de una pequeña junta militar en segundo 
término, iba a transformar poco a poco, lo que en un principio no había sido sino una pequeña insurrección campesina, en una guerra de independencia nacional ${ }^{20}$, una guerra que a la larga, tal como en Yugoslavia (1941-1945) o en Vietnam (1945-54) no podía sino beneficiar a los comunistas 21 .

Sin embargo, reiteradas veces la administración Kennedy tuvo ocasiones de orientarse hacia una solución política, saliendo honrosamente así del atolladero en que Foster Dulles había puesto a Es. tados Unidos. En junio de 1962, después de ocho meses de negociaciones, el conflicto laosiano había sido circunscrito gracias a un acuerdo aceptando la neutralidad del reino. Camboya y Francia contribuyeron eficazmente para hacer prevalecer esta solución. Es cierto que la neutralidacl pareció a algunos la única alternativa posible para la "comunización". Pero el acuerdo de Laos no era sino un test o un primer paso. No podía ser, en todo caso, efectiva si no la seguía una solución razonable de los otros problemas indochinos. Camboya, apoyada por Francia, deseaba particularmente que se iniciara una conferencia internacional que consagrara sus fronteras y su neutralidad. En lo que respecta a Vietnam del Sur, el Frente Nacional de Liberación había puesto en relieve, descle julio de 1962, el interés que tenía el acuerdo laosiano y había preconizado una solución semejante para el Vietnam del Sur22. El 20 de julio, anotaba en su programa la neutralidad de Vietnam del Sur. Aceptaba además la idea cle una confederación entre un Vietnam del Sur y una Camboya neutros.

Habría sido necesario otro gobierno en Saigón para llevar a efecto esta política de compromiso pacífico. La oposición norteamericana hizo fracasar todos los acercamientos, malograr todos los proyectos, que Moscú, Pekín y Hanoi parecían dispuestos a considerar. Por otro lado, los norteamericanos, interpretando el acuerdo laosiano como una derrota, lejos de hacer más flexible su política en Vietnam, estimularon en Diem una política más fuerte aún. En 1962 más cle 11.000 "conse-

\footnotetext{
${ }^{20}$ "Se vio a la autoridad poítica $y$ militar de Estados Unidos instalarse a su vez en Vietnam del Sur y que al mismo tiempo la guerra se reanimó alli bajo la forma de una resistencia nacional". (Charles de Gaulle, Phnom Penh, 10 de septiembre de 1966).

21'Esta guerra que beneficia al comunismo", La Croix, Paris, 7 de abril de 1965.

m Memorándum dirigido a la Conferencia de los 14 en Ginebra, por Nguyen Huu Tho, Presidente del Comité Central del Frente Nacional de Liberación, aprobando la nota enviada por el Príncipe Sihanouk a Diem el 15 de mayo de 1962. (Resumen publicado por Hsinhwa, el 6 de julio de 1962 y reproducido en Les Nonvelles du Vietnam, Paris, No 4, julio de 1962).

Ver también: Declaración del Frente de Liberación Nacional, del 20 de julio de 1962. (Las Cuatro proposiciones para la Salvación Nacional) y "Declaración del F.L.s. sobre la independencia y la neutralidad de Vietnam del Sur" (15 de agosto de 1962). Según esta última (punto 12), "Vietnam del Sur cstá listo para formar con los reinos de Kampuclea y Laos una zona de paz $y$ de neutralidad en el Sudeste asiático, conscrvando cada país su soberanía y autonomía".
} 
jeros" militares norteamericanos se infiltraron en Vietnann ${ }^{23}$. Habria que añadir a numerosos "civiles" y otros cuaclros.

La "guerra especial", la concentración de la población en "alcleas estratégicas", las operaciones brutales cle limpieza hechas por el ejército, no habían logrado sino hostilizar aún más la población del Sur. En 1963, el régimen de Saigón entraba en conflicto abierto con los budistas y comenzaba en agosto una acción armada contra sus organismos dirigentes. Simultáneamente, la guerra se extendía a todo el territorio sudvietnamita, donde el gobierno de Hanoi, a pesar de haberse mostrado favorable a la idea clel cese clel fuego, comenzaba a enviar en gran número armas y clirigentes.

Francia entonces estimó que no podía seguir callando frente a las cluras pruebas infligidas al pueblo vietnamita. En su cleclaración del 29 de agosto de 1963, el General de Gaulle expresó su convicción de que el pueblo vietnamita podría tener un papel importante en Asia "en cuanto pudiera desplegar su actividad con independencia respecto al exterior, con paz y unidad interiores y concordia con sus vecinos".

"Hoy más que nunca, es lo que Francia desea para todo el Vietnam. Naturalmente que sólo su pueblo debe elegir los medios para lograrlo, pero cualquier esfuerzo nacional hecho por Vietnam en este sentido encontraría a Francia clispuesta, en la medida de sus posibilidades, a organizar con este país una corclial cooperación"-24. El mismo día, China por boca de Mao Tse-tung, expresaba sus aprehensiones sobre el desarrollo del caso vietnamita y aseguraba a los combatientes del Frente todo su apoyo.

El problema buclista había tenido una importante repercusión en Estados Unidos. La administración Kennedy' tomaba conciencia del hecho de que Diem, lejos de servir a la causa clel "mundo libre", le hacía más bien daño. Vencer no era posible con él. En consecuencia, Washington decidía, en septiembre de 1963, cambiar no de política en Vietnam sino de cambiar el gobierno en Saigón.

París, conociendo esta nueva orientación y cacla vez más consciente del peligro que la intervención norteamericana hacía correr a la paz de Asia al incitar a la China a una réplica, estimó que había llegado el momento para entablar contactos clirectos con Pekín. Primeramente habría que conocer (sin intermediarios) la posición de China para preparar cuando llegase el momento las vías para la que en París se consideraba ya la condición sine qua non de un arreglo: el retorno progresivo a los acuerdos de Ginebra de 1954. Desde el 22 de octubre al 5 de noviembre cle 1963, Eclgar Faure estuvo en Pekín en "misión

\footnotetext{
«El número oficial de los "consejoros militares" norteamericanos de 692 en enero de 1961 , pasó a cerca de 12.000 en enero de 1962.

${ }^{24}$ Le Monde, 30 de agosto de 1963.
} 
EST U D I O S I N TER N A C I O N A L E S

oficiosa". Conferenció con Mao Tre-tung, Ghou En-lai, Liu Chao-chi, etc. Informó sobre su viaje al General de Gaulle el 28 de noviembre.

En un mes, sin embargo, la situación había evolucionado mucho. Diem había sido destituido (y muerto) el 10 de noviembre por una junta militar. Se podía aun pensar que esta junta intentaría desembarazarse - siempre que recibiese el estímulo de otros- del dominio norteamericano y se orientaría hacia un régimen "neutralista". Ia declaración de fecha $S$ de noviembre de 1963 del Frente de Liberación, abría la vía para la negociación. Pero el 22 de noviembre el Presidente Kennedy caía asesinado en Dallas. El Vicepresidente Lyndon Johnson, cuyo papel en la formación de la política vietnamita de Washington hemos visto, le sucedía.

El breve encuentro de De Gaulle-Johnson en los funerales de Kennedy y sobre todo la conferencia De Gaulle-Rusk (I6 de diciembre de 1963), convencieron al General que la política norteamericana continuaría inspirada en prejuicios sumarios y en sueños aventureros -incluso en mayor medida que antes. En París, se tuvo repentinamente conciencia exacta de los peligros que iba a correr la paz mundial debido a la obstinación de determinados hombres de buscar a cualquier precio una victoria militar en Asia. Fasta aquí no había habido la más mínima urgencia en tomar contacto con Pekín. En este momento se juzgó imposible esperar más. El contacto se estableció inmediatamente y el 27 de enero de 1964 Francia reanudaba sus relaciones diplomáticas con Pekín. Para distinguir en la que sin duda fue la base de su decisión, hay que referirse al texto exacto del párrafo esencial de la declaración del General de Gaulle, el 31 de enero de 1964:

"No hay guerra ni paz en Asia en que China no se vea implicada. Es por esto que sería absolutamente inconcebible adoptar un acuerdo eventual, de neutralidad relativa a los Estados del Sudeste asiático sin la participación de China ... neutralidad que, por definición, debería ser aceptada por todos, acreditada en el plano internacional y que excluiría, al mismo tiempo, las agitaciones armadas, sostenidas entre ellos, unos contra otros y las intervenciones multiformes del exterior, neutralidad que bien parece, en el período en que estamos, ser la única situación compatible con la vida pacífica y el progreso de los pueblos".

I.as posiciones francesas no han cambiado desde hace cuatro años. París cree aún que la solución de los problemas de esta región no puede encontrarse sino basándose en la independencia real y en la neutralidad de los estados que la componen, lo que implica y requiere la no intervención de las grandes potencias.

Los acontecimientos, desde 1964, no han hecho sino agravar las inquietudes francesas. La primera junta militar que habría podido, en 
Saigón, volver a empezar y orientar al Vietnam del Sur hacia la paz, fue destituicla el 30 de enero por generales clecididos a "guerrear". Tres clías más tarde, el Presidente Johnson inclicaba que no creía que la neutralización pudiera ser una solución y que no cabía sino "que intensificar las operaciones". El 19 cle mar\%o de 1964, un "hawk" notorio, William Buncly, sucedía a Roger Hilsman a la cabeza de la sección "Extremo-Oriente" clel Departamento de Estado. La nominación, el 30 de junio de 1964, del General Maxwell Taylor como Embajador en Saigón demostró por fin que Washington había decidido ahora extencler la guerra que el régimen de Saigón era incapaz de ganar en el Sur.

El gobierno francés ha hecho en reiteradas ocasiones proposiciones para contener el aumento constante cle la violencia. Pero ha podido constatar que cada iniciativa que tomaba con miras a facilitar un arreglo pacífico del conflicto, era seguida por una extensión de las operaciones por Estados Unidos, o por un endurecimiento que hacía cada vez más difícil la solución propuesta. Es así como en respuesta al ofrecimiento del General de Gaulle, el 23 cle julio cle 1964, de reunir en cuanto fuera posible la Conferencia de Ginebra para examinar todo el problema inclochino, el Presiclente Johnson respondió con una negativa ${ }^{25} y$ ' como poco después las operaciones iniciadas en el golfo de Tonkín por la flota norteamericana y los comandos sudvietnamitas llegaron a los incidentes que ya conocemos, de los que la Casa Blanca se sirvió para obtener rápidamente del Congreso plenos poderes ( 7 cle agosto de 1964). Es así como, frente a las sugerencias de buscar rápidamente una negociación que Francia (como también la Unión Soriética) intentaba en Washington en febrero cle 1956, la Administración Johnson respondió con el bombardeo de Vietnam del Norte, lanzánclose así en una agresión caracterizada contra el campo socialista; un año más tarde, en enero cle 1966, cuando Francia recomendaba prolongar indefinidamente la tregua de los bombardeos para permitir entablar conversaciones con Hanoi, el Presidente Johnson prefirió el blitz (3I de enero cle 1966).

No hay duda cle que la política estadouniclense en el Vietnam ha sido una cle las causas principales de la crisis de la Alianza Atlántica. Ya a partir cle 1956, la administración norteamericana decidía todo lo relativo al Vietnam del Sur por sí misma, colocanclo permanentemente a sus aliados ante hechos consumados. Pero, a partir de 1961, con el Presidente Kennedy, dicha Administración adoptó en el Vietnam una política $y$ una estrategia que al menos en lo que a Francia se refiere

xpresidente Johnson: "We do not believe in conferences called to ratify terror" (New York Times, 25 de julio de 1964) (No creemos en conferencias convocadas para ratificar el terror). 
E S T U D I O S I N T E R N A C I O N A L E S

(el país occidental que mejor conoce la Indochina) se considera errónea, cruel, sin relación con los antecedentes profundos de la situación $y$ potencialmente muy peligrosa para el porvenir cle las relaciones entre Asia y Europa. A comienzos de 1966 se hizo evidente que, por su política asiática de tipo macarthuriano, el Presiclente Johnson corría el riesgo de arrastrar a Europa y al Mundo Occidental a una aventura.

Es significativo (aunque raras veces puesto en relieve por los observadores) que haya siclo el 7 de marzo, cinco semanas después de la reanudación del blitz contra Vietnam, que el General de Gaulle anunciara el retiro de Francia de la oTAN y despidiera a las fuerzas norteamericanas que permanecían en Francia ${ }^{26}$. La política norteamericana en Vietnam tomaba un cariz tal que París no podía ya aceptar por más tiempo ningún liderazgo norteamericano en el oeste, ni una integración de las fuerzas militares. Por lo demás, el ejemplo de Vietnam mostraba la naturaleza cle la 'protección' norteamericana (el país 'protegido' era devastado sin piedad). Es por los medios políticos y diplomáticos (apertura al este) que de ahora en adelante París buscará activamente un escape que se esperaba haría un día inútil la presencia militar norteamericana en Europa continental.

Disociánclose abiertamente de la política norteamericana en Asia, Francia demostraba al Tercer Mundo que las soluciones concebidas por Washington no eran las únicas que el Occiclente podía ofrecer. El General de Gaulle protegía así las posibilidades de Occiclente y evitaba que Asia perdiera las esperanzas en este último ${ }^{27}$. Daba a entender a todos que cuanclo Washington hablaba de "The West", el mundo debía comprender "los anglosajones" y' que ni Francia, ni Alemania, ni los Estados Escandinavos, etc., estaban incluidos automáticamente. Creemos que ofrecer una alternativa razonable y cuerda a la política norteamericana para que no todo el Occidente sea hecho responsable por los pueblos pobres del "johnsonismo": es una de las explicaciones esenciales, pensamos nosotros, de la política asián tica y africana del General de Gaulle.

El gobierno francés juzga a la vez "cletestable", "odiosa" y "sin esperanza" la tentativa cle Estados Unidos de imponer su protectorado a Vietnam del Sur. Cualesquiera que fuesen los motivos de la intervención, cualesquiera que fuesen los éxitos momentáneos o aparentes de la fuerza mecánica superior (incluso aplastante) de que el Pentá-

^Al anunciar al gobierno su decisión de retirarse de la otas, el General de Gaulle habría agregado: "No estamos dispuestos a acompañar a los norteamericanos en todas las aventuras en que se les ocurra lanzarse".

:Comentario del Príncipe Silanouk (junio de 1964): "Sin Francia habríamos perdido la esperanza en occidente'. De la misma manera llegan cartas del mundo entero, actualmente, al senador W. Fulbright, diciendo en resumen: "Sin ustẹdes habriamos perdido toda esperanza en América". 
gono dispone, no podemos imaginar ya que una potencia blanca - sobre todo de espíritu conservador- pueda imponer en forma duradera a asiáticos un nuevo régimen colonial. Los franceses, que tienen de Indochina una larga y a veces amarga experiencia, no pueden dudar al respecto que el nacionalismo vietnamita, sosteniclo por China, la Unión Soviética y un número creciente de pueblos, terminará por rechazar la intervención norteamericana, tal como venció las invasiones de los mongoles o de los chinos y más recientemente el régimen colonial impuesto por Francia misma.

En París se cree hoy en clía que atrapada en el engranaje fatal en que las consideraciones cle prestigio y de "credibiliclad" dominan, la Administración Johuson, más que cambiar de política, no ofrece ya a los vietnamitas sino elegir entre la capitulación y la destrucción. EI Estado Mayor norteamericano ha tomado en sus manos la guerra, en la que las tropas norteamericanas asumen la carga principal ${ }^{28}$. Los sudvietnamitas no están ya en su país sino como ejecutantes?. La ideología se ha hecho secundaria. Para los que en Francia se interesan en el problema, se trata primero de salvar al pueblo vietnamita de esta destrucción, del genocidio, y como lo dijo el Secretario General de la ONU, U Thant, en unas palabras: de ayudarlo a sobrevivir. LLa comunidad internacional puede acaso dejar que una gran nación riquísima aplaste a un pequeño pueblo pobre? Es sin ducla, esta la concepción que tiene hoy día el General de Gaulle cuando califica al conflicto de "detestable" y "odioso".

No se trata solamente de denunciar o de protestar. Se trata también de ayudar a los vietnamitas a recobrar su independencia y soberanía. En efecto, en París se estima que la independencia de Vietnam no es solamente el derecho más sagrado de los vietnamitas, sino también el único medio de eliminar las intrigas extranjeras que amenazan la paz internacional en esta región.

Al respecto, Francia piensa que la tentativa de Estados Unidos de erigir al Vietnam del Sur como un bastión anglosajón antichino puede agravar las tensiones en Asia, más que reducirlas. Asimismo, le asiste el convencimiento de que no hay solución posible del conflicto contra

ssRemitirse a Marvin L. Stone, Is U.s. trapped in a "Jopeless war"?, U.S., News and World Report, dicicinbre 5 de 1966 , pp. $\$ 0-49$.

29 Las decenas de millares de norteamericanos, coreanos, australianos que desembarcan y combaten en Vietnam del Sur no están bajo mando vietnamita ni aun nominalmente, csto ha creado y crea numerosos disgustos entre "aliados". Varios oficiales, generales sudvietnamitas, entrevistados por el autor, consideran que Washington ya no ayuda a Vietnam a enfrentar una crisis $y$ que los vietnamitas ya no son más que peones en un jucgo que ellos ya no controlan en ninguna etapa. Según fuentes bien informadas, la participación de las tropas surcorcanas en el conflicto fue durante meses el objeto de discusiones difíciles entre las autoridades de Saigón y el Embajador de Estados Unidos, el General Marwell Taylor. El gobierno de Saigón se vio obligado a aceptarlo, bajo una fuerte presión norteanericana. (Remitirse a France-Asie/Asia, París, No 187, otoño de 1966, I) 116). 
ES T U D I O S I N T ER N A G I O N A L E S

China (siendo ella vecina $y^{\prime}$ poclerosa tendrá siempre los medios para reconsiderar su posición); que Pekín no puede aceptar en Indochina la presencia permanente de Estados Uniclos y que no hay, por lo tanto, una solución valedera para el conflicto si acaso Estados Unidos, como China, no acepta permanecer completamente fuera del territorio inclochino.

Francia, por otra parte, está convencida de que si la existencia de dos Vietnam será probablemente un hecho cierto aun por varios años, sería a la vez inmoral e inadmisible buscar una solución de tipo coreano, que a la larga sería contraria a las aspiraciones del pueblo vietnamita $y^{\prime}$ a los compromisos solemnes adoptados en repetidas ocasiones por Francia y sus aliados. Al igual que China o la Unión Soviética, Francia no puede aceptar una anexión por la fuerza de Vietnam del Sur a la "zona de prosperidad" que Estados Unidos se ha propuesto constituir en el Extremo Oriente. Consentirlo sería reconocer la primacía de la fuerza en las relaciones internacionales, crear un precedente que sería seguido tápidamente por una acción semejante contra el 'dominó' siguiente (Camboya o Birmania).

Por estas razones se podría resumir que por lo menos mientras el General de Gaulle dirija su política, Francia no reconocerá ninguna solución o decisión que consagre de una u otra forma, una división política permanente clel Vietnam $y$ una presencia política o militar norteamericana en ese país.

\section{CÓMO RESTABLECER LA PAZ EN INDOGHINA}

Excluyenclo "cualquier solución militar" y en general cualquier solución por la fuerza ${ }^{30}$ del problema vietnamita, el General de Gaulle ha repetido numerosas veces que a su entender no se podía terminar con el conflicto sino por la negociación. ¿Qué solución política pro* pone o sugiere?

\footnotetext{
30Después de la reiniciación de los bombardeos nortcamericanos en Vietnam del Norte el gobierno francés publicó, el 2 de febrero de 1966, un comunicado donde dice particularmente:

"El gobierno francés pucde sólo sentir y desaprobar la reiniciación de los bombardeos. El cstablecimicnto de la paz en Vietnam implica, en efecto y ante todo, conforme a los acuerdos de Ginebra, la renuncia a cualquier intervención cxterior. Esta acción renovada de bombarcleo, además de agravar cruelmente la suerte de las pollaciones, compromete aún más la causa de la paz".

"Excluimos cualquier solución militar $y$ no aprobamos que los combates se prolonguen, " fortiori, que scan extendidos con cl pretexto de obtenerla". (Carta del General de Gaulle al Presidente Ho Chi Minh, del 8 de febrero de 1966).

"Francia considera que los combates que azotan a Indochina no traen consigo... ninguna salida. Según ella, es poco probable que el aparato bélico norteamericano llegue a ser anjquilado en el lugar mismo; por otra parte, no hay ninguna posibilidad de que los pueblos de Asia se sometan a la ley del extranjero ilegado de allende el Pacifico, cualesquicra que puedan ser atts intenciones. Sólo un acuerdo político podría entonces restablecer la paz, a menos que el universo ruede hacia la catástrofe. ." (Charles de Gaulle, discurso de Phnom Fenl, el 1" de sep)tiembre de 1966).
} 
Sus proposiciones básicas están contenidas esencialmente en tres textos: Su carta al Presiclente Ho Chi Minh (clel 8 de febrero de 1966); su discurso con ocasión de la visita clel rey de Laos a París (el 13 de julio de 1966); el cliscurso que pronunció el 19 de septiembre de 1966 en el estadio de Phnom Penh.

Al Presidente Ho Ghi Minh, el General de Gaulle escribía:

"Una solución política presenta evidentemente un doble aspecto; vietnamita por una parte, puesto que sin hablar de la reunificación ulterior, se trata de que la población de Vietnam del Sur pueda, sin la intervención del exterior, constituir un gobierno representativo, lo que no podrá de todas maneras ser realizado mientras la guerra continúe. Por otra parte, un aspecto internacional, puesto que se trata de que sean renovados y por supuesto respetados, los compromisos tomados en 1954 respecto de la independencia y de la neutralidad de Vietnam y de la noingerencia de otros en sus asuntos interiores, lo que evidentemente es contradictorio con la actual situación...".

En Phnom Penh, la misma idea fue expresada con algunas precisiones complementarias:

"Al igual que el de 1954, el acuerdo tendrá por objeto restablecer y asegurar la neutralidad de los pueblos de Indochina y su derecho a autodeterminarse, dejando a cada uno de ellos la responsabilidad completa de sus asuntos. Los contratantes serían entonces los poderes reales que se abocarían a ello y entre los otros Estados por lo menos las cinco potencias mundiales...".

El General de Gaulle había cleclarado antes, al rey de Laos, que Francia estaba "dispuesta a participar activamente en una negociación internacional", pero...

"para que pueda abrirse y llegar a buen fin una negociación de esta indole, es necesario sin duda alguna que se vuelva primero a lo que había sido aceptado y aplicado hace doce años, es decir al término efectivo de la intervención extranjera y a la neutralidad de los Estados de esta región. Así como también es necesario que una garantía conjunta de los Estados interesados sea organizada y especialmente de las cinco principaies potencias del mundo".

Las etapas del arreglo del conflicto aparecen claramente en estos textos. La clave del problema, su exigencia básica si se pudiera decir, es la independencia y la representatividacl de las autoridades de Saigón. ¿Cómo instaurar un régimen representativo en el Sur? Tal es el primer problema a resolver. Y sólo podrá serlo cuando Washington acepte dejar a los sudvietnamitas clecidir libremente su destino.

Se podría pensar que si Estados Unidos hubiese dejado por lo menos que la Asamblea "elegida" en 1966 clesignara a un gobierno 
civil capaz de imponer su autoridad a los militares, a la vez que buscara en condiciones determinadas un cese del fuego con el Frente Nacional de Liberación, se habría podiclo considerar la formación en Saigón de un ejecutivo provisorio de una independencia intaclable que habría podiclo, en espera de la aceptación de todos los inte. resados en un proceso constitucional, hacerse cargo en nombre de Vietnam del Sur de los compromisos de neutralidad previstos y acelerar la particla de las tropas norteamericanas.

En efecto, no es sino clescle los momentos en que tome forma la unión nacional que podrá abrirse la negociación internacional con resultados positivos, la que clebería consagrar el fin de la intervención. extranjera en Vietnam, reconocer: solemnemente la independencia $y^{\prime}$ la neutralidad de los Estados Indochinos y organizar la garantía de Ios acuerdos

Probablemente conversaciones útiles se habrían podido empezar descle hace tiempo, si ilusiones sobre la posibilidad de una victoria militar no prevaleciesen en Washington, incitando a la Administración Johnson a formular exigencias inaceptables y a hacer vanos los acercamientos pacíficos. Al respecto, la manera de reaccionar del Presidente de Estados Unidos frente a la proposición correcta de Hanoi con fecha 28 de enero de 1967, no hizo sino confirmar cle manera evidente lo que Paris sabe desde hace tiempo, que no es Vietnam del Norte el que bloquea la iniciación de conversaciones. Desde marzo cle 1965 se sabe en efecto que conversaciones entre Hanoi y Washington habrian podido tener lugar en cualquier momento, si la Casa Blanca hubiere aceptado poner fin incondicionalmente $\mathrm{y}$ definitivamente a los bombardeos del Norte. Lo que no se sabe tan bien, es que no podrian entablarse negociaciones verdaderas sino en la medida en que Estados Unidos aceptara, para comenzar, reconocer los acuerdos de Ginebra y, en particular, se comprometiera solemnemente a retirar sus fuerzas de Vietnam. En lo que a esto se refiere, el gobierno francés aprueba fundamentalmente la posición tomada por el gobierno de Hanoi. Desde el 2 de febrero de 1966 el General de Gaulle condenó la reanudación de los bombarcleos norteamericanos sobre Vietnam del Norte y precisó a Phnom Penlı el 19 de septiembre cle 1966:

"La posibiliclad y con mayor razón la apertura de una negociación tan vasta y difícil, dependería evidentemente de la decisión y del compromiso que habría aceptado Norteamérica de repatriar a sus fuerzas en un plazo conveniente y determinado" 31 .

arLa misión de Jean Sainteny en Hanoi (lin de junio de 1966) y la conversación que había tenido en Phnom Penh con el Embajador de la República Democrática de Vietnam, Nguyen 
Washington ha manifestaclo cierta irritación ante estas tomas de posición calificadas de unilaterales $y^{\prime}$ ha juzgado que ellas impeclirian a Francia hacer el papel de mediadora que llegado el momento algunos esperan de ella. Al respecto, sería conveniente precisar claramente la posición básica del gaullismo. Francia -el General de Gaulle ha clicho expresamentej" - no intentari ninguna mediación en este confliclo. El Victnam es actualmente objeto de una invasión extranjera llevada a cabo violando numerosos compromisos internacionales. Es evidente que nacla puede intentarse, en el plano diplomático, mientras el invasor no haya, por lo menos, hecho saber su voluntad de poner fin a su acción ${ }^{3: !}$.

En Vietnam, al menos para Francia, no se puecle poner en el mismo plano a norvietnamitas y norteamericanos. Son los sudvietnamitas $-y$ no los norteamericanos- los que se encargaron en 1959 de una parte de las responsabiliclacles asumiclas por los franceses en 1954 .

Para París, Estados Unidos no tiene ningún derecho a intervenir en Indochina, menos aún que cualquier otra potencia, puesto que son los únicos de los Cinco Grancles que rehusaron asociarse a las decisiones de Ginebra.

París no reconoce pues sino a los vietnamitas. Aunque distingue a sureños de norteños, el gobicrno estima sin embargo, que en clerecho no hay más que un Vietnam que dos gobiernos rivales se disputan (el de Saigón y el de Hanoi) $)^{t}$ que una línea provisoria de demarcación separa las zonas de administración. Para los franceses que tienen cierta experiencia en lo que a líneas de clemarcación se refiere, no puede haberlas en zonas de "agresión internacional". La insurrección campesina de 1957-1958 se ha converticlo en el Sur en un pocleroso movimiento de liberación nacional. Combatientes del Norte participan ahora en el movimiento, pero para los franceses que conocen la situación estos norteños que vienen a aýuclar a sus hermanos del Sur con armas chinas o soviéticas son tan "agresores" como lo eran los paracaiclistas franceses libres con armas inglesas en la Francia ocupada, o los particlarios italianos que venian atravesando los Apeninos a contribuir en la clestrucción de la república mussoliniana

Thuong, le habia permitido al General de Gaulle conocer exactamente en qué condiciones estimaba posible una negociación el gobierno de Hanoi (ver Ph. Devillers, "La clé de la pajx est a V'ashingtou", Le Monic, 15 de septiembre de 1966 y Io Vima, Alenas, 17 de septiembre de 1966).

3ł". . Ninguma mediación ofrecerá tma perspectiva de exito $y$ es por eso çue Francia por su parte nunca ha pensado ni piensa proponer ninguna" (Charles de Gaulle, discurso de Phnom Penh, el 14 de septiembre de 1966).

s'La posición del gobierno de Hanoi al resjecto es prácticamente irléntica a la que habria adoptado durante la guerra de Coren la Administración norteamericana con respecto a Pyong Yang y Pekín. Waslingtou clebía entonces repetir lasta el cansnucio que no podín laber negociación mientras el agresor no lubiera sido replegado al paralelo 38. 
cle Salo. La tesis de "la agresión norteña" no es aceptada en Francia3t. Por lo demás, aceptar el paralelo 17 como frontera de Estado sería para Francia renegar de todos los compromisos que ella contrajo con el Vietnam nacional. Los patriotas vietnamitas no se lo perdonarian. Toclavía se recuerda bastante bien en París lo que fue el Comité de Liberación Nacional de 194:3-44 para comprender en su justo valor las posiciones del Frente Nacional de Liberación de Vietnam clel Sur.

Por lo tanto, si Francia preconiza una solución política basada en la independencia total de Vietnam, su neutraliclad militar y la autodeterminación de su pueblo, es porque ella estima que esta solución es la menos dañina y la menos peligrosa de todas. Unicamente la neutralidad de los Estados indochinos puede, a su entender, "evitarles... transformarse en un terreno de confrontamiento para las clominaciones e ideologías rivales" (De Gaulle, Phnom Penh, 19 de septiembre de 1966) y permitirles consoliclarse (Camboya es un ejemplo excelente). En efecto, las alineaciones provocan infaltablemente divisiones y rivaliclades políticas que clividen las uniclades nacionales, favorecen las intrigas extranjeras y crean una inestabilidad permanente paralizando el desarrollo económico. Por otra parte, las alineaciones acarrean inevitablemente un aumento de los gastos militares que economías nacionales básicamente agrícolas e insuficientemente desarrolladas no pueden soportar. La ayuda extranjera en estas condiciones se transforma rápidamente en una verdadera intervención desembocando en la creación de castas militares, cuyos sueldos son pagados en general a través cle cliversos intermediarios con créditos extranjeros. La neutralidad, puesto que reduce las cargas militares que entorpecen el clesarrollo, puesto que ella aplaca las pasiones políticas, es en sí un factor poderoso de progreso y de paz.

De manera general $-\gamma$ esto sobrepasa largamente el marco indochino- el gobierno francés estima que no se deben escatimar esfuerzos para ayudar a los Estados del Sudeste asiático a resistir contra las presiones e ingerencias extranjeras, lo que les permitiría consagrar: sus energías y sus recursos a las tareas esenciales: la educación de las masas, el desarrollo económico, la lucha contra la pobreza, la enfermedad y la desigualdad. Al respecto, siendo el nacionalismo y el cleseo de progreso económico y social las fuerzas dominantes en esta región, cualquier intervención cle una potencia blanca a favor de clases privilegiadas no puede sino suscitar un aumento de la hostilidad hacia

aPor otra parte, contradiciéndole, las autoridades de Saigón han declararado oficialmente que el número de hombres "infiltrados" del Norte habia sido de 300 en 1959 y 2.700 en 1960 (Discurso de Tran Van Do, Mínistro de Relaciones Esteriores de Saigón en Nucva Delhi, junio de 1965). Por otra parte, a comienzos de 1959, la guerra ya lacía estragos en el delta del Mekong. Ello no podía haber sicio provocado por 300 homlses. 
Occidente y la ruptura de uniones nacionales a menudo todavía frágilmente establecidas.

En Washington, se critica la "lalta de realismo" de la posición francesa ${ }^{\prime}$ se invoca para clesacreditarla la amenaza china. A decir: verdacl las amenazas, más o menos imaginarias por lo clemás, que las administraciones norteamericanas sucesivas ponen en relieve para justificar la expansión continua clel poclerío económico militar y clel dispositivo estratégico de Estados Uniclos, no impresionan ya al gobierno francés, como lo testimonian las últimas sesiones de la OTAN. Un examen retrospectivo del período de la "guerra fría" ha demostrado por lo demás la nulidad de la mayoria de estas pretendiclas "amenazas". En el presente caso, París no cree en absoluto en la existencia de planes funclamentalmente ofensivos de Clina en el sudeste cle Asia. El gobierno chino está preocupado aparentemente del desarrollo económico $y$ social de China y su política exterior considerada fríamente, sin prejuicios ni obsesión, es fundamentalmente defensiva, aun cuando se exprese frecuentemente en términos violentos: se trata de impedir a Estados Unidos de hacer del Extremo Oriente su nuevo "Far-Twest".

En este campo, Francia que ha entablaclo relaciones normales con Pekín, espera defencler plenamente su libertad cle acción y no dejarse arrastrar a un conflicto que podría suscitar alguna acción inconsiderada cle la aclministración norteamericana ${ }^{35}$.

De todas maneras - y volvicndo a Vietnam- el gobierno francés estima que la solución que preconiza no presenta riesgos considerables ni para Estados Uniclos ni para los Estaclos no indochinos del Sudeste cle Asia.

Para empezar, no se cree en París que el Frente Nacional de Liberación cle Vietnam clel Sur sea un instrumento de Hanoi. Las sectas político-religiosas dieron origen a la guerrilla clel Sur y fueron el núcleo del Frente (en 1957-1958). Son, lo sabemos, exclusivamente sureños. Los antiguos Viet Minh y los comunistas, que tienen hoy clía un papel importante pero no dominante en el Frente, son prácticamente todos sureños; son incluso, en su mayoría, nativos del sur de Ban Me Thuot. El objetivo del Frente, clescle sus origenes hasta ahora, ha sido obtener que se constituya en Saigón un gobierno vercladeramente representativo de la población del Sur. Un gobierno tal, aunque lo compusieran varios miembros comunistas, no sería "ni un gobierno comunista" ni un satélite de Hanoi. De todas maneras,

"La "Losición de Francia", ha dicho el General de Gaulle, está lijada en particular por "su resolución de no estar, donde sea y suceda lo que suecda, automáticamente implicada en la extensión eventual del drama $y$ de guardar en todos los casos libertad de acción" (Charles de Gaulle, Plnom Penl1, 19 de septicmbie de 1966). 
los acuerdos de Ginebra no han prohibido jamás a ningún partido (Viet Minh o comunista, etc.), ejercer su actividad en Vietnam del Sur. Ellos solamente hicieron que la lucha traspasara del plano militar al plano político.

Después de 22 años cle guerra casi ininterrumpicla, un gobierno de coalición en Vietnam del Sur no adoptaría ciertamente una politica con miras a provocar nuevas intervenciones extranjeras en su suelo. Se puede presumir que haría lo necesario para mantener la neutralidad del país y la unión de las fuerzas nacionales del Sur. Tendría sin duda los medios para consolidar la independencia gracias a la ayuda económica que recibirá probablemente de parte de Europa (occidental y oriental), de Estados Unidos y de China.

En la medida en que este gobierno de coalición estimaría conveniente negociar con posterioridacl con el Norte, para restablecer por etapas la uniclad del Vietnam, no se cree en París que un desarrollo cle esta indole afectaría peligrosamente el equilibrio cle las fuerzas de la región.

De todas maneras, un Vietnam fuerte e independiente, aun gobernado o dominado por: comunistas, opondría a cualquier intervención extranjera (china u otra) una barrera ciertamente más eficaz que la de un país dirigiclo por una oligarquía de privilegiados cuyo derrocamiento por el movimiento nacional, lo impiden únicamente los "Marines" norteamericanos. Y no vemos por qué este Vietnam lastimado, devastado, que tiene tanto $y$ tendría tanto que hacer para sí, arruinaría su amistacl con Laos y Camboya por una reanudación de su expansión territorial. En cuanto a Tailandia, Birmania o Malasia, no existe entre ellos y Vietnam ninguna frontera común, ningún diferenclo antiguo o reciente, nacla sino un interés común en mantenerse lejos de la rivalidad de los gigantes de este mundo.

La seguridad de Estaclos Uniclos no estaría en absoluto amenazada por la neutralidad de Indochina, así como tampoco ningún interés vital norteamericano. Como lo dijo muy bien Foster Dulles, el 11 de mayo de 1954, el Sudeste asiático puede ser defendido sin Indochina. Con la 7a Flota que permanecería en el Mar de China, con las bases formidables de Tailandia, de las Filipinas, de Okinawa y de Guam, no se ve lo que Estados Uniclos pueda temer cle una Indochina neutra, puesto que conservaría a su clisposición muy cerca e intactos, todos los medios para un eventual contrataque.

El gobierno norteamericano invoca los compromisos que ha tomado y que debería cumplir. ¿De qué compromisos se trata? ¿De la carta del Presidente Eisenhower a Diem clel 23 de octubre de 1954? 
En ella no se trataba sino de una ayuda económica y era condicional. Por lo demás Diem no cumplió con las condiciones solicitadas. ¿Y el tratado de la OTASE? No permite actuar sino a pedido expreso del estado amenazado $y^{\prime}$ en casos precisos bien definidos. ¿Cuándo ha el gobierno de Saigón acucliclo a la OTASE? ¿Cuando ha la OTASE adoptado la clecisión común requerida? La intervención de la OTASE, como se sabe, no podrá decidirse sino por unanimidad ${ }^{30}$. ¿Acuerdos bilaterales norteamericano-vietnamitas? Los compromisos de Diem en 1956, a pedido expreso de Estados Uniclos, prohibían al Vietnam cualquier alianza militar y toda entrada de tropas extranjeras. Para París la intervención norteamericana no se basa en ningún acuerdo válido $y$ no tiene tampoco un funclamento juríclico ${ }^{3 T}$; es contraria a los acuerdos de Ginebra, al tratado de Manila, a la carta de la oNU y, por último a los acuerclos franco-norteamericanos de septiembre $y$ de diciembre de 1954 que subordinaban a las autoriclades francesas las misiones norteamericanas $y$ obligaban a ambos países a consultarse para actuar conjuntamente. No existiendo de hecho en la base de la intervención norteamericana en el Vietnam más que compromisos personales de John F. Kennedy, Lyndon B. Johnson, Dean Rusk $y^{\prime}$ Robert MCNamara, tomados clescle $196 \mathrm{I}$ ante algunos personeros vietnamitas cuya legitimidad y representatividad son dudosas.

Para el General de Gaulle, los Estados Unidos se honrarian ellos mismos si aceptaran cambiar cle política en Vietnam, como Francia lo supo hacer en Argelia. Sin duda el interés profundo de Norteamérica no es tratar de inponer una solución militar en Indochina, en beneficio de grupos impopulares y corrompidos. Los Estados Unidos repiten hoy en día en Vietnam $y^{\prime}$ Laos lo que trataron infructuosamente de hacer en China en 1945-1949. Ahora bien, ya se sabe cómo la historia juzga a la política norteamericana de ayuda al Kuomintang... Por su política en Vietnam el Presidente Johnson ha llevado

aeEn París predomina la opinión que tomando en cuenta las explicaciones proporcionadas por el Secretario de Estado Foster Dulles, en el momento de la ratificación del Tratado de Manila, el párrafo I, del artículo IV, de dicho tratado, no puede aplicarse, sino en el caso de un ataque armado abierto de tipo convencional y clásico $y$ no en el caso de subversión. De todas maneras, la convención de armisticio de 195f, que el gobierno de Saigón habia prometido respetar en 1956, habia obligado a las partes a remitirse en caso de violencia primero a la conferencia de Ginebra. En 1956, el gobierno Diem se labifa comprometido a no aceptar ninguna tropa extranjera y a no conceder ninguna base militar. No podía por lo tanto apelar en ningún caso a la ayuda de Estados Unidos únicamente.

En cuanto al párrafo 2, que se aplica a la "subversión", no prevé sino consultas, con miras a una acción común. El gobierno de Washington no ha hecho estas consultas; ha decidido solo, una intervención que es, por lo tanto, contraria al párrafo 1 y al párrafo 2.

37Sobre la legalidad de la acción norteamericana en Vietnam, ver "Memorandum of Law of Lawyers' Committee on American Policy Towards Vietunm", anexo al discurso del senador Wayne Morse, 23 de septiembre de 1965 (Congressional Record, 23 de septiembre de 1965) y Quincy Wright, "Legal Aspects of the Vietnam Situation", American Journal of International Law. octubre de 1966 , pp. $750-770$. 
ES T U D I OS I N T E R N A C I O N A T E S

por sí mismo, independientemente, su destino ${ }^{43}$. El tiene en todo caso deseo de ejercer una influencia "en el sentido requerido para apresurar el término del conflicto" y de "participar activamente en su solución en cuanto esta parezca posible". Y mantenclrá a este efecto todos los contactos útiles, en particular con Hanoi, Phnom Penh, Moscú $y$ hasta con Pekín mismo. Un día vendrá que esperamos próximo en que la raxón y la humanidad se trasladen al centro de la decisión; día en que tal vez el General de Gaulle encuentre a veces un cierto $\mathrm{eco}^{4-4}$.

Ciertamente el gobierno clel General de Gaulle no está apoyado por una opinión francesa obsolutamente unánime en esta política vietnamita. Pero hay que constatar que pocos problemas cuentan con un consenso tan amplio hoy clía en Francia. Desde la U.D.v ${ }^{\mathbf{a}}$ República al Partido Comunista, pasando por la Federación de la Irquierda o el P.s.u., la posición del Presidente de la República sobre Vietnam es aprobadat5. La rechazan solamente los partidos o formaciones en que dominan todavía los protagonistas de la primera guerra de Vietnam y de la guerra de Argelia, los promotores de la "experiencia Bao Dai"ta o los abogados de una Cruzada Antibolchevique. Este "partido de guerra" perdió en Francia en 1954, luego en 1962. Subsiste pero es minoritario y es significativo ver que en Francia los únicos que sostienen hoy día la política norteamericana, son los que desde 1945 a 1962 se han opuesto a la descolonización.

Cualesquiera sean los obstáculos o las dificultades, sin lugar a dudas Francia proseguirá la política que ha sido descrita, que es armónica tanto con los compromisos adquiridos por ella como con

\footnotetext{
${ }^{12} \mathrm{La}$ junta militar de Saigón está sostenida principalmente por refugiados norteños (sobre todo católicos) que han traspasado sus resentimientos y sus métodos al Sur. Es significativo que para secundar su política anticomunista, Estados Unidos no haya, prácticamente, encontrado en Vietnam del Sur, sino que emigrados norteños.

"No hace mucho tiempo que Walter Lippmann ha escrito de la siguiente manera: "El secreto del General de Gaulle es que muy a menudo ha tenido razón desde el principio y que ha sido el primero en sentir lo inevitable que sucederfa algún dia" (IVorld Journal Tribune, Nueva York, 29 de noviembre de 1966).

itRemitirse a las declaraciones de Piurre Mendès-France (Le Nouvel Observateur, No 91; 10 de agosto de 1966), Goy Mollet y François Mfitterrand (Le Monde, 14 de junio de 1966) y la resolución final del 100 Coloquio Jurídico, 9 de octubre de 1966 (Le Monde, 11 de octubre de 1966), que constituyen una posición común a toda la izquierda. Mendès-France piensa nún que el General de Gaulle no actúa lo suficiente en el sentido que predicn ("Le problème le plus grave en 1967". Le Nouvel Obscrvateur, $N^{*} 116$ (19 de febrero de 1967) y No 117 (8 de febrero de 1967)).

${ }^{49}$ Aun Jean Lecanuet (que fue uno de los colaboradores de Jean Letourneau, Ministro de los estados asociados), dijo el 12 de septiembre de 1966 por televisión: "Creo que los norteamericanos, cuando recurricron a los bombardeos cometieron un grave error: un error político, pues eso no trajo modificaciones al pensamiento de Ho Chi Minh y a su gobierno; un error militar, pues no hay un resultado tangible; un crror también del punto de vista humano $y$ moral, porque toda masacre de poblaciones civiles es abominable. . Creo que tenemos el mayor interés en proponer a los norteamericanos que se desliguen de Indochina, después de firmar un acuerdo $y$ es probablemente en ese punto en que podriamos variar nuestras posiciones... (Le Monde, 14 de septiembre de 1966).
} 
la moral internacional. Es tanto, en efecto, lo que está en juego, que París no puede transigir. La paz sigue siendo el objetivo central de la política francesa tanto en Extremo Oriente como en cualquier otra parte. Una paz verclaclera, aquella que clefinía Santo Tomás de Aquino como la "tranquilidad en el orclen" y' no "la paz clel clesierto", a la que se refería Tácito. El General de Gaulle, consciente del peligro de la guerra ${ }^{4}$, ha analizado y pesaclo las condiciones concretas de una paz duraclera que el gobierno francés propone hace ya seis años - con soluciones que no son por cierto fáciles, pero que al menos tienen el mérito no sólo de ser las menos malas, sino sobre todo de conducir a la pacificación ${ }^{48}$ y no al genocidio o a la guerra general.

26 de diciembre de 1967

Este artículo fue publicado originalmente en Politique Elrangère (Paris), y ha sido traducido con permiso del autor.

Ha declaración que el Genernl de Gaulle hizo al Consejo de Ministros del 21 de junio de 1967 es con respecto a esto muy significativa: "El espíritu y el hecho de la guerra se extienden de nuevo en el mundo. Un conflicto contribuyc a suscitar a otro.

"La guerra desatada en Vietnam nor la intervención norteamericana, la destrucción de vidas y bienes que acarrea, la esterilidad fundamental que de ella es la marca, no pueden dejar de propagar la confusión no sỏlo en el lugar, sino más lejos, por muy poderosos que sean los medios empleados y terribles que sean sus efectos.

"De ahi viene la actitud de China y el apuro de su armamentismo. Por otra parte, de alí viene el proceso psicológico y político que en Mfedio Oriente desembocó en la lucha.

"Francia se opone a la guerra en Vietnam $y$ a la intervención extranjera, que es la causa de ella. Desde el origen, ella sostiene que este conflicto podría terminar solamente con el compromiso aceptado por Norteamérica de retirar sus fuerzas en un plazo determinado...

"Desde que la guerra se extendió al Medio Oriente, Francin considera que no hay ningunn probabilidad de llegar a un arreglo pacífico en Ia actual situación mundial, a menos que aparezca un elemento mundial nuevo. Este podrín y debería ser el fin de la guerra en Victnam, $y$ por el térnino que se pondría a la intervención extranjera...."

Pierre Dumas, a la salida clel Consejo, declaró que para el gobierno francés "el conflicto vietnamita la originado los problemas con los que nos enfrentamos actualmente. El gobierno cree que nos estamos hundiendo en un proceso que no puede conducir sino a la guerra mundial, si hay que resolver los problemas recurriendo a la violencia" (Le Mrinde, 22 de junio de 1967 ). ${ }_{45}$ Sobre "La vie d'une paix honorable", ver Le Monde, 22.23 de octubre de 1967. 